\title{
The role of neutrophils in immune dysfunction during severe inflammation
}

\author{
Pieter H. C. Leliefeld ${ }^{1,3^{*}}$, Catharina M. Wessels ${ }^{1}$, Luke P. H. Leenen ${ }^{1}$, Leo Koenderman ${ }^{2,3}$ and Janesh Pillay ${ }^{3,4}$
}

\begin{abstract}
Critically ill post-surgical, post-trauma and/or septic patients are characterised by severe inflammation. This immune response consists of both a pro- and an anti-inflammatory component. The pro-inflammatory component contributes to (multiple) organ failure whereas occurrence of immune paralysis predisposes to infections. Strikingly, infectious complications arise in these patients despite the presence of a clear neutrophilia. We propose that dysfunction of neutrophils potentially increases the susceptibility to infections or can result in the inability to clear existing infections. Under homeostatic conditions these effector cells of the innate immune system circulate in a quiescent state and serve as the first line of defence against invading pathogens. In severe inflammation, however, neutrophils are rapidly activated, which affects their functional capacities, such as chemotaxis, phagocytosis, intra-cellular killing, NETosis, and their capacity to modulate adaptive immunity. This review provides an overview of the current understanding of neutrophil dysfunction in severe inflammation. We will discuss the possible mechanisms of downregulation of anti-microbial function, suppression of adaptive immunity by neutrophils and the contribution of neutrophil subsets to immune paralysis.
\end{abstract}

\section{Background}

Severe inflammation induced by trauma, sepsis or ischemia/reperfusion injury is known to contribute to devastating complications such as acute respiratory distress syndrome (ARDS) and (multiple) organ failure [1]. This has been attributed to microvascular dysfunction, tissue damage and dysregulation of metabolism caused by severe inflammation [2]. In recent years, however, it has been recognised that severe systemic inflammation can also result in a profound 'compensatory' downregulation of immune responses, rendering the host susceptible to infections or unable to clear existing infections [3]. Although conceivably an evolutionarily preserved response to protect the host from immunemediated tissue damage, downregulation of antimicrobial immunity creates an unwanted consequence: susceptibility to bacterial infections such as caused by Staphylococcus aureus, Pseudomonas aeruginosa and Escherichia coli as well as opportunistic fungal infections

\footnotetext{
*Correspondence: plelief2@umcutrecht.nl

'Department of Surgery, University Medical Center Utrecht, Utrecht, The Netherlands

${ }^{3}$ Laboratory of Translational Immunology, University Medical Center Utrecht, Utrecht, The Netherlands

Full list of author information is available at the end of the article
}

such as (disseminated) candidiasis [4-6]. In addition, reactivation of viruses such as cytomegalovirus are found in critically ill patients [7]. These findings clearly indicate that both the innate and the adaptive immune system are dysfunctional in these patients. Nosocomial infections in critically ill patients are associated with an increased length of hospital stay, increased health care costs and profound additional morbidity and mortality [8].

Neutrophils, effector cells of the innate immune system, are abundantly present in the circulation and comprise up to $50-70 \%$ of total circulating leukocytes in humans. The enhanced frequency and severity of bacterial and fungal infections in patients with congenital neutrophil disorders demonstrate that neutrophils are indispensable for adequate protection against microbes [9]. Patients suffering from leucocyte adhesion deficiency (LAD)-I are at risk for development of necrotizing infections and sepsis because of inadequate neutrophil transendothelial migration to the site of infection [10]. The Chediak-Higashi syndrome and chronic granulomatous disease (CGD) underscore the eminent importance of intracellular bacterial killing by neutrophils. ChediakHigashi syndrome is caused by a mutation in the LYST gene, which encodes a lysosomal trafficking regulator [11]. The mutation leads to the absence of a proper 
formation of phagolysosomes. Patients suffering from Chediak-Higashi are extremely susceptible to pyogenic infections and this syndrome is usually fatal before the age of 10 [11]. CGD is characterised by a defect in production of the bactericidal reactive oxygen species (ROS) due to defective NADPH oxidase and results in recurrent infections, reducing life-expectancy significantly [12]. In murine models of sepsis, knockout of essential neutrophil antimicrobial functions leads to rapid death. For instance, mice lacking the neutrophil granule proteins myeloperoxidase or elastase die more rapidly from sepsis $[13,14]$. Apart from the severe phenotypes seen in patients with inborn errors and murine knockout models, more subtle effects were seen in a murine sepsis model where rapid death coincided with inadequate phagosomal acidification of neutrophils after phagocytosis [15]. These studies highlight the generally accepted importance of neutrophils in antimicrobial defence in acute inflammatory models. In addition, they demonstrate disturbances in the anti-microbial functionality of these cells during severe inflammation.

In this review we will discuss neutrophil functions required for adequate microbial defence and the mechanisms leading to neutrophil-mediated immune dysfunction.

\section{Functions of neutrophils associated with anti-microbial defence Chemotaxis}

The controlled process of phagocytosis and killing of microbes by neutrophils firstly requires chemotaxis towards the site of infection. Chemotaxis is the propensity of cells to migrate in the direction of gradients of chemotactic stimuli [16]. The ability to adequately sense chemotactic gradients is one of the final capabilities acquired by neutrophils during maturation in the bone marrow and this functionality appears to be the most sensitive to perturbations in vivo and in vitro [17]. Impairment of chemotaxis has been described in a wide variety of diseases associated with increased susceptibility to infections: diabetes mellitus, viral infections (influenza), cytomegalovirus, HIV and tropical diseases (malaria) [18-22]. In sepsis, chemotaxis of neutrophils is impaired through various mechanisms [23-25]. Interleukin (IL)-33 limits this impairment by preventing downregulation of CXCR2 and improves outcome in a murine model [26]. In humans, extensive research has focused on the chemotactic capacity of neutrophils from burn patients. It has been shown that neutrophils from thermally injured subjects are characterised by impaired chemotaxis, both in vivo in the tissue and in vitro, towards the bacterial peptide fMLF, which is believed to contribute to the increased susceptibility to infections in this group of patients [27, 28].

\section{Intracellular killing}

Once neutrophils have found and recognised a pathogen, phagocytosis can take place and subsequent bacterial killing occurs in the phagolysosome. Neutrophils possess two separate but intercalating anti-microbial mechanisms, one dependent on oxygen and the other independent of it. Although categorisation of killing mechanisms in this manner creates a comprehensive understanding, it does not reflect the in vivo situation in which both systems operate simultaneously. Furthermore, it is likely that the individual significance of both killing mechanisms shifts during the course of inflammation. This is due to fluxes in oxygen demand and supply caused by dynamic tissue perfusion and oxygenation during the inflammatory response [29].

The oxygen-dependent mechanisms are mediated by ROS downstream of $\mathrm{O}_{2}^{-}$formed by the NADPH oxidase complex [30]. In short, upon activation of a neutrophil, either via ingestion of bacteria or by extracellular stimuli, the NADPH oxidase complex is assembled from both cytosolic and membrane-bound components [31]. The active oxidase complex transports electrons from cytosolic NADPH across the membrane to the electron acceptor, molecular oxygen, generating superoxide anion [29]. This is in turn metabolises in the phagosome into highly bactericidal end products, such as hydroxyl radical, hydrogen peroxide and hypochlorous acid [31]. In sterile inflammation, such as trauma or acute liver failure, neutrophils are known to produce elevated levels of spontaneous ROS [32, 33]. Furthermore, ROS production in these patients in response to a stimulus is strongly elevated in comparison with that found in neutrophils from healthy controls; a process generally referred to as priming [27, 34-36]. Uncontrolled release of ROS by neutrophils accumulating in vascular beds can contribute to loss of endothelial barrier integrity and subsequent vascular leakage, predisposing patients to organ injury as a result of pro-inflammatory complications (acute lung injury, ARDS) [37, 38]. This hypothesis is in line with the findings of increased ROS production in trauma patients developing ARDS in comparison with control trauma patients [39]. In addition, the observation that neutrophils from patients with fatal sepsis are characterised by markedly increased production of ROS compared with survivors is noteworthy [40].

Granule products comprise the backbone of nonoxidative killing by neutrophils [41]. The azurophilic granule is a reservoir of serine proteases: neutrophil elastase, cathepsin G, proteinase 3, and azurocidin [42]. These digestive proteases are delivered into the phagolysosome upon fusion of granules with a phagosome containing bacteria. During maturation of the phagolysosome the intraphagosomal $\mathrm{pH}$ is rigorously altered. The early shift of intraphagosomal $\mathrm{pH}$ towards an alkaline 
level ( $\mathrm{pH}$ 8.5-9.5) due to dismutation of $\mathrm{O}_{2}{ }^{-}$provides the initial milieu for the proper activation of proteases, leading to optimal microbicidal and digestive function of these enzymes [43]. Concomitant with the waning of production of ROS the phagosome progressively acidifies, coinciding with granule-phagosome fusion. These granules contain the $\mathrm{Na}^{+} / \mathrm{H}^{+}$-antiporter V-ATP-ase, which is responsible for pumping of protons into the phagosome [44-46]. Neutrophils of burn-injured patients are characterised by dysfunctional $\mathrm{pH}$ control of their phagolysosomes since these patients fail to demonstrate transient phagosomal alkalinisation in the first 5 minutes and acidify promptly after ingestion of bacteria [47]. This situation might lead to improper activation of the proteases and impaired killing of ingested microbes. On the other hand, deficient acidification of peritoneal neutrophils in a murine model of sepsis was associated with increased mortality [15]. These findings demonstrate the importance of adequate intraphagosomal $\mathrm{pH}$ regulation for microbial control.

The presence and proper function of granules intracellulary are crucial as these organelles supply neutrophils with an arsenal of antimicrobial mechanisms. However, uncontrolled activation of neutrophils in an inflammatory microenvironment can lead to collateral tissue damage by excessive extracellular degranulation and the release of neutrophil proteases. Neutrophil extravasation, homing and activation are mediated by activation of several surface receptors, including $\beta 2$ integrins, complement receptors, Fc $\gamma$-receptors, and formyl peptide receptors. Uncontrolled activation of neutrophils is mediated through these same receptors by responding to aberrant production of chemokines, cytokines and release of extracellular peptides [48]. During this process granules fuse with the plasma membrane, releasing their content into the environment [49]. More tissue damage will lead to increased influx and activation of neutrophils, which then leads to a vicious cycle of tissue destruction [50].

\section{Neutrophil extracellular traps}

In addition to conventional intracellular killing and degradation of individual bacteria, the concept of extracellular killing by neutrophils using neutrophil extracellular traps (NETs) has received much attention during the past decade [51, 52]. NETs consist of fibrils formed by active expulsion of DNA, chromatin and granule proteins from neutrophils $[52,53]$. They are formed in response to a variety of pro-inflammatory stimuli of which IL-8, tumour necrosis factor-alpha and lipopolysaccharide are the most relevant [54]. During formation of NETs neutrophils die and this process is generally referred to as NETosis. This form of cell death is dependent on the NADPH-oxidase complex since neutrophils treated with the pharmacological NADPHoxidase inhibitor DPI and CGD patients are unable to release NETs [53]. In vitro NETs were shown to be a cell-death-associated event occurring hours after stimulation [53]. However, intravital microscopy revealed viable neutrophils after formation of NETs and the resulting anuclear neutrophils were subsequently capable of phagocytosis and formation of mature phagosomes. These data indicate that NETosis does not necessarily result in cell death [55]. The direct bactericidal properties of NETs are a topic of discussion, and prevention of bacterial dissemination in vivo might be their main function [56]. Apart from this antimicrobial function, the cytotoxicity of NETs can be harmful to the host if their release is inappropriately controlled. NETs are released following sepsis, trauma and ischemia-reperfusion injury and a growing body of evidence shows they can contribute to tissue destruction, as reviewed by Liu et al. [57] The potential of NETs to cause tissue destruction was elegantly demonstrated in a murine model of primary graft-dysfunction after lung transplantation [58]. In addition, several studies argue that NETs might be involved in triggering auto-immune diseases since autoantibodies against NET constituents (e.g. DNA) are often found in these diseases [59, 60]. Although NETs have firmly established their tissue-damaging properties, scepticism still exists about the in vivo anti-microbial relevance of NETs [61].

\section{Neutrophil dysfunction in acute inflammation}

The mechanisms involved in adequate anti-microbial defence can also disrupt subsequent immunity. This is caused by aberrant control of their own essential antimicrobial arsenal, such as: (1) auto- and paracrine cleavage of essential surface receptors; (2) downregulation of surface receptors and signalling pathways in nonresolving inflammation or during a second microbial hit following initial sterile inflammation (damage-associated molecular pattern (DAMP)-microbe-associated molecular pattern (MAMP) interference); and (3) the release of neutrophil populations with decreased microbicidal properties. In addition, neutrophils in inflammatory conditions can affect other immune cells and contribute to immune paralysis of the adaptive immune system.

Proteolytic cleavage by neutrophil-derived proteases and downregulation of immune receptors

Serine proteases released by neutrophils influence the expression of receptors critical to neutrophil-microbial interactions (Fig. 1a). Apart from stimulatory effects through serine protease activated receptors (PARs), they can downregulate immune responses by cleaving 
A
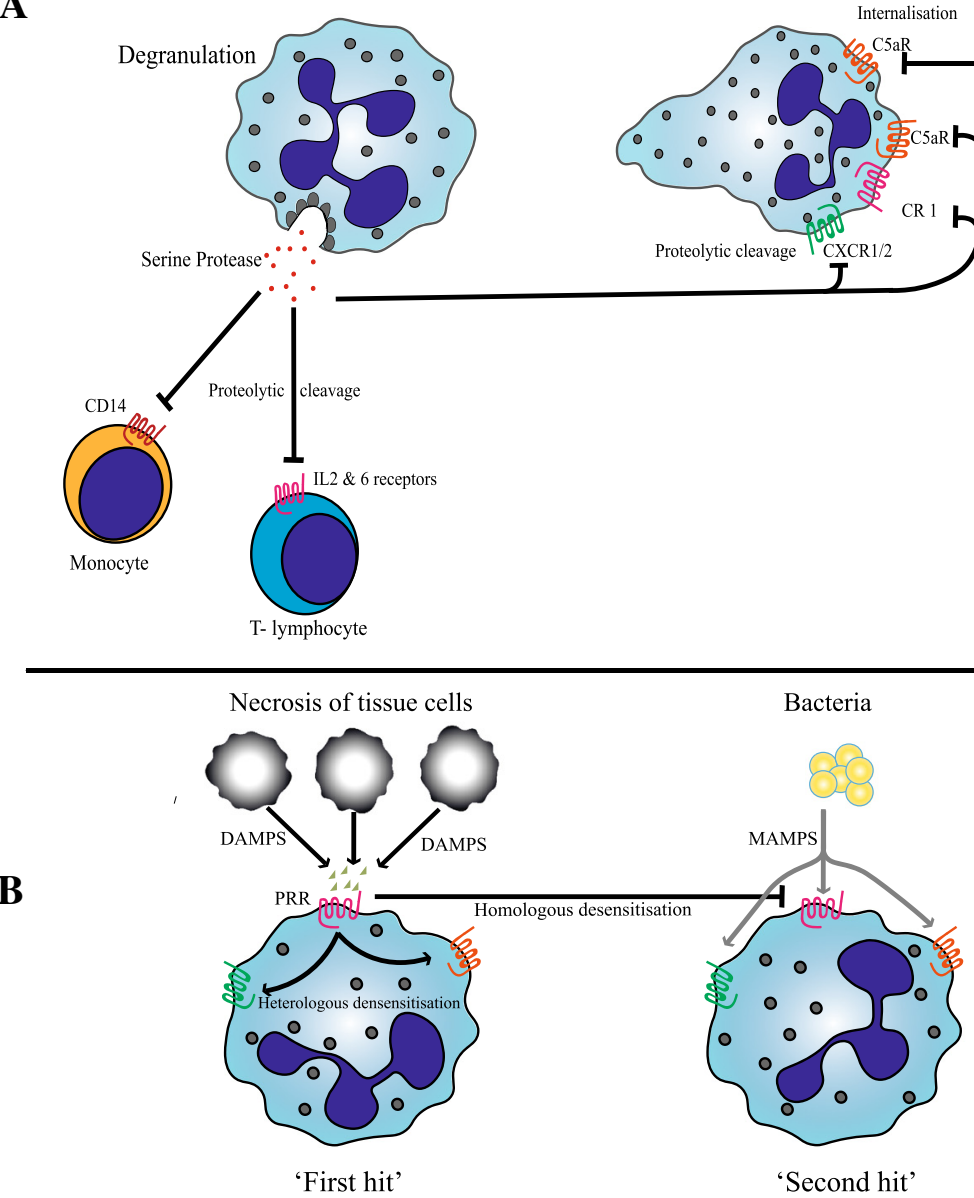

Fig. 1 Downregulation of immune receptors by serine proteases from degranulated neutrophils and desensitisation by pattern recognition receptors. a Schematic representation of downregulation of receptors on neutrophils, monocytes and lymphocytes during inflammation due to cleavage by neutrophil serine proteases after degranulation. Binding of $\mathrm{C} 5 \mathrm{a}$ to neutrophils results in internalisation of C5aR. Decreased expression of these receptors impairs neutrophil effector functions during subsequent challenges. b Biological mimicry between DAMPs and MAMPs. Danger signals derived from necrotic tissue cells ("First hit") bind to pattern recognition receptors (PRRs) and limit subsequent responses to microbial signals ("Second hit") through homo- and heterologous desensitisation. DAMP damage-associated molecular pattern, IL interleukin, MAMP microbe-associated molecular pattern

essential receptors on the surface of both adaptive and innate immune cells [62]. For instance, neutrophil elastase cleaves CXCR1, a receptor for IL-8, on the surface of neutrophils $[63,64]$. This mechanism is relevant during acute inflammation in which circulating neutrophils from trauma and sepsis patients selectively downregulate CXCR2, the only other neutrophil receptor for IL-8 [65, 66]. Tarlowe et al. [67] provided evidence that downregulation of this receptor preceded the occurrence of pneumonia in critically ill trauma patients. Downregulation of CXCR2 and cleavage of CXCR1 would result in severe hyporesponsiveness to IL-8, an important neutrophil chemoattractant.

Furthermore, neutrophil serine proteases can cleave complement receptors such as the CR1 receptor (CD35) and $\mathrm{C} 5 \mathrm{aR}(\mathrm{CD} 88)$ on neutrophils $[68,69]$. These receptors are important as they mediate chemotaxis, degranulation and proper recognition of opsonised microbial targets by CR1 and C5aR, respectively [70]. During inflammation, decreased expression of $\mathrm{C} 5 \mathrm{aR}$ is seen due to engagement and subsequent internalisation. This can result in a profound defect in neutrophil phagocytosis of subsequent pathogens as C5a-induced chemotaxis is important for neutrophils to find opsonised targets [71]. Proteases not only inhibit the function of neutrophils, they can also affect monocytes in the micro-environment. Neutrophil elastase cleaves $\mathrm{CD} 14$, a receptor necessary for the high affinity recognition of lipopolysaccharide by TLR4, thereby impairing proper bacterial recognition by monocytes [72]. Lastly, elastase and cathepsin G mediate shedding of cytokine receptors for IL-2 and IL-6 on $\mathrm{T}$ lymphocytes [73]. 


\section{DAMP-MAMP interference}

Trauma and ischemia/reperfusion injury can evoke the release of large amounts of cellular components from necrotic cells. These intracellular constituents are known as damage-associated molecular patterns (DAMPS). They are host-derived and serve as important proinflammatory non-microbial stimuli after injury [74]. Since the development of the 'danger hypothesis' by Matzinger [74], a large number of studies have focussed on molecules driving this response. The most extensively studied DAMPS are high-mobility group box 1, heat shock proteins, ATP, uric acid, formylated peptides from mitchondria and mitochondrial DNA [75-80]. Inflammation induced by pathogens on the other hand is mediated through microbial constituents referred to as microbe-associated molecular patterns (MAMPS), which resemble DAMPS and, importantly, share similar pattern recognition receptors (PRRs) on the neutrophil [81]. This biological mimicry and utilisation of similar receptors creates a problem for the immune system since injury (DAMPS) causes downregulation of many of these receptors by hetero- and homologous desensitisation. This can render neutrophils unable to mount an adequate response to a subsequent microbe (MAMP) (Fig. 1b). To illustrate the relevance of this phenomenon, Zhang et al. [80] showed the release of vast amounts of mitochondrial formylpeptides into the circulation of major trauma patients. These molecules stimulate neutrophils via formyl peptide receptor 1 (FPR1), an important receptor in recognizing microbes that produce danger signals by release of formyl-peptides [80] (Fig. 1b). It was shown that heterologous desensitisation of chemokine receptors and homologous desensitisation of FPR1 occurred simultaneously, predisposing trauma patients to infection [82].

\section{Release of incompetent neutrophil populations}

Much of the work detailed in the previous sections did not take into account the variations in functional phenotypes that appear in the circulating neutrophil compartment during severe inflammation. After maturation neutrophils are retained in the bone marrow via expression of chemokine receptor CXCR4 (ligand CXCL12), whilst CXCR2 (ligands IL-8/CXCL1 and 2) controls release into the peripheral blood. Inflammatory stimuli can induce the release of neutrophils by disrupting the balance in CXCR4/CXCL12 signalling through various mechanisms [60]. In severe inflammation large numbers of neutrophils are released into the circulation from the bone marrow post-mitotic pool as well as from the marginated pool (i.e. neutrophils not freely circulating but attached to the microvasculature) [83]. Under these conditions we have previously shown that peripheral neutrophils consist of heterogeneous subsets with different priming states and function [84]. During severe inflammation a large number of immature or banded cells appear in the circulation and even neutrophil progenitor cells can be identified. As a result, persistent severe inflammation might lead to "bone marrow exhaustion" of neutrophils, which is thought to inevitably result in a state of compromised innate immunity [85]. At present, however, it is unclear how to interpret the presence of immature cells in the bloodstream in response to inflammation. It might be a compensatory response initiated by the depletion of mature neutrophils in the bone marrow or a dedicated inflammatory reaction to a bacterial stimulus. Our data support the first hypothesis since these immature neutrophils also show a pronounced decrease of various receptors in comparison with their mature circulating counterparts [84]. In addition to the IL-8 receptors (CXCR1 and CXCR2) and the C5a receptor, the $\mathrm{Fc}_{\mathrm{C}}$ receptors (CD16 and $\left.\mathrm{CD} 32\right)$, which are important in pathogen recognition, phagocytosis and killing, are also downregulated on immature cells (Fig. 2) [84]. Relatively few studies have assessed the functionality of immature and progenitor neutrophils subsets in severe human inflammation. In septic patients, immature neutrophils were shown to have decreased phagocytic capacity [86]. Importantly, reduced phagocytosis and increased numbers of circulating neutrophil progenitors are both associated with poor outcome in septic patients as well as in patients with severe inflammation $[87,88]$.

\section{Suppression of adaptive immunity by neutrophils}

Neutrophils have long been recognised as professional killers. Eradication of bacteria and fungi was thought to be their main task. Evidence is, however, accumulating that apart from their direct anti-microbial function, neutrophils participate in subsequent modulation of (adaptive) immune responses in severe inflammation [89-91]. Under these inflammatory conditions, neutrophils produce chemokines and secrete granule contents which can subsequently attract and modulate the function(s) of $\mathrm{T}$ cells both directly and indirectly $[92,93]$. For instance, neutrophil elastase reduces expression of co-stimulatory molecules by dendritic cells, limiting maturation and induction of a proper Th1 response [94]. In addition, $\mathrm{T}$ cells in the inflammatory microenvironment may be affected by neutrophil elastase by cleavage of their IL-2 and IL-6 receptors (Fig. 1a) [95]. Another mechanism of immune-modulation was observed in macrophages after phagocytosis of apoptotic neutrophils. Under these conditions immune responses of macrophages shift towards a more anti-inflammatory cytokine profile [96]. Furthermore, neutrophils themselves have been shown to produce anti-inflammatory cytokines such as IL-1ra and IL-10 [97]. However, the evidence 

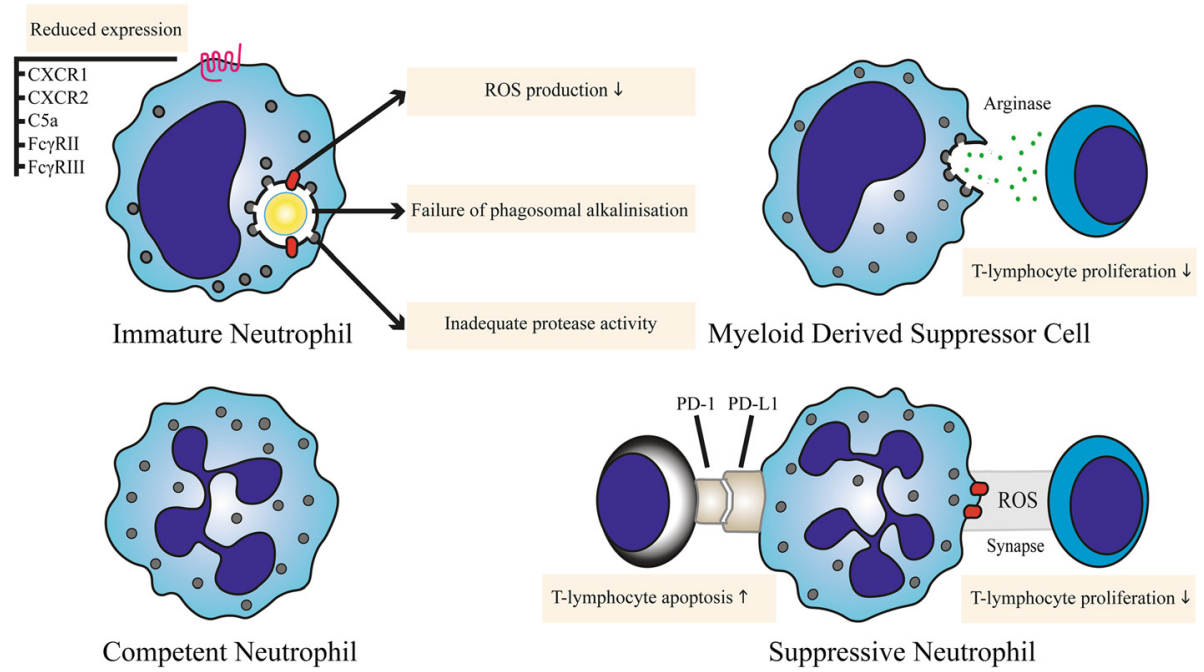

Fig. 2 Circulating neutrophil subsets in severe inflammation. At least four types of neutrophils circulate in the bloodstream of patients during severe inflammation: immature, competent and suppressive neutrophils and myeloid-derived suppressor cells. Mechanisms contributing to immune dysfunction are displayed for neutrophils from different subsets. ROS reactive oxygen species

regarding IL-10 production by neutrophils is controversial, as it has only been shown in mice with mycobacterial infections [98]. In humans neutrophils are unable to produce IL-10 [99]. Direct regulation of T-cell responses by neutrophils is slowly becoming an established concept. A large body of evidence demonstrates that a heterogeneous group of immature mononuclear cells and neutrophils termed myeloid-derived suppressor cells (MDSCs) can suppress T-cell responses in several murine tumour models. In addition, these cells have been shown to play a role in various models of infectious diseases, organ transplantation and autoimmune diseases [100]. Identification of human immature granulocytic MDSCs has proven to be challenging though. In particular, their differentiation from mature neutrophil phenotypes seen in the blood during acute inflammation remains to be established, as we have reviewed in detail elsewhere [101]. The mechanisms by which MDSCs can suppress $\mathrm{T}$ cells include the expression and secretion of arginase-1, which depletes arginine from the microenvironment (Fig. 2) [102]. Depletion of L-arginine, which is an essential amino acid, results in cell cycle arrest of $\mathrm{T}$ cells in the G0-G1 phase [103]. Furthermore, in human inflammation we and others have observed a population of mature CD62 $\mathrm{L}^{\mathrm{dim}}$ neutrophils capable of suppressing T-cell responses through a mechanism which relies on ROS release in an immunological synapse [104]. Recently, similar neutrophils in septic shock patients have been found to express arginase- 1 and suppress T-cell functions [105]. Another mechanism by which neutrophils might inhibit T-cell responses is through PD-L1 [106]. Neutrophils isolated from sepsis patients express the surface protein PD-L1, a potent inducer of apoptosis in $\mathrm{T}$ cells. The underlying mechanism of PD-L1 expression is an interferon-gamma-dependent process [106]. The PD-1-PD-L1 axis is thought to be an important mechanism in immune suppression in septic patients by inducing lymphocyte apoptosis and monocyte dysfunction [107]. Blocking this axis after the induction of sepsis by administering a PD-1-blocking antibody improved survival in mice [108]. This suppressive mechanism might be protective in tissues with severe inflammatory infiltrates. On the other hand, this process might be unwanted when neutrophils migrate to lymph nodes and engage with adaptive immunity, as has been described under various conditions [109]. In these lymph nodes neutrophils are able to inhibit humoral immune responses through interaction with $\mathrm{T}$ and $\mathrm{B}$ lymphocytes $[109,110]$.

\section{Conclusion}

Severe inflammation can result in immune paralysis through various mechanisms. We propose that neutrophils play a central role in this process, either through decreased antimicrobial functions or through direct suppression of (adaptive) immunity. Many experimental studies have been performed addressing the damaging role of neutrophils, which contributes to organ failure in severe inflammation. However, their role in immune paralysis remains understudied. Studies to explore their causative role in susceptibility to infections in animal models of severe inflammation should be designed. Decreased neutrophil antimicrobial functions and their ability to suppress adaptive immunity in vitro should be 
considered as important patient outcomes. This approach is necessary to increase understanding of the role of neutrophils in immune paralysis leading to detrimental outcome in post-surgical, post-trauma and septic patients.

\section{Abbreviations}

ARDS: acute respiratory distress syndrome; CGD: chronic granulomatous disease; DAMP: damage-associated molecular pattern; IL: interleukin; MAMP: microbe-associated molecular pattern; MDSC: myeloid-derived suppressor cell; NET: neutrophil extracellular trap; ROS: reactive oxygen species.

\section{Competing interests}

The authors declare that they have no competing interests.

\section{Authors' contributions}

PHCL designed search strategies, undertook search strategies, screened search results, organised retrieval of papers, appraised quality of papers and extracted data from papers, drafted the manuscript and wrote the review. CMW designed search strategies, undertook search strategies, screened search results, organised retrieval of papers, appraised quality of papers and extracted data from papers, drafted the manuscript and wrote the review. LPHL participated in designing this review, wrote the review and provided general advice on and coordinated the review. LK participated in designing this review, wrote the review and provided general advice on and coordinated the review. JP participated in designing this review, designed search strategies, undertook search strategies, screened search results, organised retrieval of papers, appraised quality of papers and extracted data from papers, drafted the manuscript and wrote the review. All authors participated in editing of the manuscript and approved the final version.

\section{Acknowledgments}

JP was supported by the Lung Foundation the Netherlands (grant number 5.2.14.058JO).

\section{Author details}

'Department of Surgery, University Medical Center Utrecht, Utrecht, The Netherlands. ${ }^{2}$ Department of Respiratory Medicine, University Medical Center Utrecht, Utrecht, The Netherlands. ${ }^{3}$ Laboratory of Translational Immunology, University Medical Center Utrecht, Utrecht, The Netherlands. ${ }^{4}$ Department of Anesthesiology and Critical Care, University Medical Center Utrecht, Utrecht, The Netherlands.

\section{Published online: 23 March 2016}

\section{References}

1. Lord JM, Midwinter MJ, Chen Y-F, Belli A, Brohi K, Kovacs EJ, et al. The systemic immune response to trauma: an overview of pathophysiology and treatment. Lancet. 2014;384:1455-65.

2. Singer PM, De Santis V, Vitale D, Jeffcoate W. Multiorgan failure is an adaptive, endocrine-mediated, metabolic response to overwhelming systemic inaflammation. Lancet. 2004;364:545-8.

3. Boomer JS. Immunosuppression in patients who die of sepsis and multiple organ failure. JAMA. 2011;306:2594.

4. Martin SJ, Yost RJ. Infectious diseases in the critically ill patients. J Pharm Pract. 2011;24:35-43.

5. Vincent J-L, Rello J, Marshall J, Silva E, Anzueto A, Martin CD, et al. International study of the prevalence and outcomes of infection in intensive care units. JAMA. 2009;302:2323-9.

6. Viale P. Candida colonization and candiduria in critically ill patients in the intensive care unit. Drugs. 2009;69 Suppl 1:51-7.

7. Mansfield S, Grießl M, Gutknecht M, Cook CH. Sepsis and cytomegalovirus: foes or conspirators? Med Microbiol Immunol. 2015;204(3):431-7.

8. Cobb JP, Buchman TG, Karl IE, Hotchkiss RS. Molecular biology of multiple organ dysfunction syndrome: injury, adaptation, and apoptosis. Surg Infect (Larchmt). 2000;1:207-13.

9. Dinauer MC. Inherited neutrophil disorders: molecular basis and new therapies. Hematology. 2000;2000:303-18.
10. Anderson DC, Springer TA. Leukocyte adhesion deficiency: an inherited defect in the Mac-1, LFA-1, and p150,95 glycoproteins. Annu Rev Med. 1987;38:175-94.

11. Kjeldsen L, Calafat J, Borregaard N. Giant granules of neutrophils in ChediakHigashi syndrome are derived from azurophil granules but not from specific and gelatinase granules. J Leukoc Biol. 1998:64:72-7.

12. Holland SM. Chronic granulomatous disease. Hematol Oncol Clin North Am. 2014;27:89-99.

13. Belaaouaj A, McCarthy R, Baumann M, Gao Z, Ley TJ, Abraham SN, et al. Mice lacking neutrophil elastase reveal impaired host defense against gram negative bacterial sepsis. Nat Med. 1998:4:615-8.

14. Gaut JP, Yeh GC, Tran HD, Byun J, Henderson JP, Richter GM, et al. Neutrophils employ the myeloperoxidase system to generate antimicrobial brominating and chlorinating oxidants during sepsis. Proc Natl Acad Sci U S A. 2001;98:11961-6.

15. Chiswick EL, Mella JR, Bernardo J, Remick DG. Acute-phase deaths from murine polymicrobial sepsis are characterized by innate immune suppression rather than exhaustion. J Immunol. 2015;195:3793-802.

16. Zigmond $\mathrm{SH}$. Mechanisms of sensing chemical gradients by polymorphonuclear leukocytes. Nature. 1974;249:450-2.

17. Boner A, Zeligs B, Bellanti J. Chemotactic responses of various differentational stages of neutrophils from human cord and adult blood. Infect Immun. 1982;35:921-8.

18. Wierusz-Wysocka B, Wysocki H, Siekierka H, Wykretowicz A, Szczepanik A, Klimas R. Evidence of polymorphonuclear neutrophils (PMN) activation in patients with insulin-dependent diabetes mellitus. J Leukoc Biol. 1987:42:519-23.

19. Larson HE, Parry RP, Tyrrell DA. Impaired polymorphonuclear leucocyte chemotaxis after influenza virus infection. Br J Dis Chest. 1980;74:56-62.

20. Bale JF, Kern ER, Overall JC, Baringer JR. Impaired migratory and chemotactic activity of neutrophils during murine cytomegalovirus infection. J Infect Dis. 1983;148:518-25.

21. Martin LS, Spira TJ, Orloff SL, Holman RC. Comparison of methods for assessing chemotaxis of monocytes and polymorphonuclear leukocytes isolated from patients with AIDS or AIDS-related conditions. J Leukoc Biol. 1988;44:361-6.

22. de Leoratti FMS, Trevelin SC, Cunha FQ, Rocha BC, Costa PAC, Gravina HD, et al. Neutrophil paralysis in plasmodium vivax malaria. PLoS Negl Trop Dis. 2012;6:e1710

23. Reddy RC, Standiford TJ. Effects of sepsis on neutrophil chemotaxis. Curr Opin Hematol. 2010;17:18-24.

24. Reddy RC, Narala VR, Keshamouni VG, Milam JE, Newstead MW, Standiford TJ. Sepsis-induced inhibition of neutrophil chemotaxis is mediated by activation of peroxisome proliferator-activated receptor\{gamma\}. Blood. 2008;112:4250-8.

25. Rios-Santos F, Alves-Filho JC, Souto FO, Spiller F, Freitas A, Lotufo CMC, et al. Down-regulation of CXCR2 on neutrophils in severe sepsis is mediated by inducible nitric oxide synthase-derived nitric oxide. Am J Respir Crit Care Med. 2007;175:490-7.

26. Alves-Filho JC, Sônego F, Souto FO, Freitas A, Verri W, Auxiliadora-Martins M, et al. Interleukin-33 attenuates sepsis by enhancing neutrophil influx to the site of infection. Nat Med. 2010;16:708-12.

27. Dong YL, Abdullah K, Yan TZ, Rutan T, Broemeling L, Robson M, et al. Effect of thermal injury and sepsis on neutrophil function. J Trauma. 1993;34:417-21.

28. Butler KL, Ambravaneswaran V, Agrawal N, Bilodeau M, Toner M, Tompkins RG, et al. Burn injury reduces neutrophil directional migration speed in microfluidic devices. PLoS One. 2010:5:e11921.

29. Nauseef WM. How human neutrophils kill and degrade microbes: an integrated view. Immunol Rev. 2007;219:88-102.

30. Babior BM. NADPH oxidase: an update. Blood. 1999;93:1464-76.

31. Bedard K, Krause K-H. The NOX family of ROS-generating NADPH oxidases: physiology and pathophysiology. Physiol Rev. 2007;87:245-313.

32. Liao Y, Liu P, Guo F, Zhang Z-Y, Zhang Z. Oxidative burst of circulating neutrophils following traumatic brain injury in human. PLoS One. 2013;8:e68963.

33. Taylor NJ, Nishtala A, Manakkat Vijay GK, Abeles RD, Auzinger G, Bernal W, et al. Circulating neutrophil dysfunction in acute liver failure. Hepatology. 2013:57:1142-52.

34. Hietbrink F, Koenderman L, Althuizen M, Pillay J, Kamp V, Leenen LPH. Kinetics of the innate immune response after trauma: implications for the development of late onset sepsis. Shock. 2013;40:21-7. 
35. Botha J, Moore FA, Moore EE, Kim FJ, Banerjee A, Peterson VM. Postinjury neutrophil priming and activation: an early vulnerable window. Surgery. 1995;118:358-64. discussion 364-5.

36. Taylor JV, Gordon LE, Hall H, Heinzelmann M, Polk HC. Differences between bacterial species shown by simultaneous assessment of neutrophil phagocytosis and generation of reactive oxygen intermediates in trauma patients. Arch Surg. 1999;134:1222-7. discussion 1227-8.

37. Mittal M, Siddiqui MR, Tran K, Reddy SP, Malik AB. Reactive oxygen species in inflammation and tissue injury. Antioxid Redox Signal. 2014;20:1126-67.

38. Fox ED, Heffernan DS, Cioffi WG, Reichner JS. Neutrophils from critically ill septic patients mediate profound loss of endothelial barrier integrity. Crit Care. 2013;17:R226.

39. Simms HH, D'Amico R. Increased PMN CD11b/CD18 expression following post-traumatic ARDS. J Surg Res. 1991;50:362-7.

40. Santos SS, Brunialti MKC, Rigato O, Machado FR, Silva E, Salomao R, Generation of nitric oxide and reactive oxygen species by neutrophils and monocytes from septic patients and association with outcomes. Shock. 2012;38:18-23.

41. Borregaard N, Cowland JB. Granules of the human neutrophilic polymorphonuclear leukocyte. Blood. 1997;89:3503-21.

42. Spicer SS, Hardin JH. Ultrastructure, cytochemistry, and function of neutrophil leukocyte granules. A Rev Lab Invest. 1969;20:488-97.

43. Levine AP, Duchen MR, de Villiers S, Rich PR, Segal AW. Alkalinity of neutrophil phagocytic vacuoles is modulated by HVCN1 and has consequences for myeloperoxidase activity. PLoS One. 2015;10:e0125906.

44. Cech P, Lehrer RI. Phagolysosomal pH of human neutrophils. Blood. 1984;63:88-95.

45. Bassøe CF, Laerum OD, Glette J, Hopen G, Haneberg B, Solberg CO. Simultaneous measurement of phagocytosis and phagosomal pH by flow cytometry: role of polymorphonuclear neutrophilic leukocyte granules in phagosome acidification. Cytometry. 1983;4:254-62.

46. Nanda A, Brumell JH, Nordström T, Kjeldsen L, Sengelov H, Borregaard N, et al. Activation of proton pumping in human neutrophils occurs by exocytosis of vesicles bearing vacuolar-type $\mathrm{H}+-$ ATPases. J Biol Chem. 1996;271:15963-70.

47. Bjerknes R, Vindenes H, Pitkänen J, Ninnemann J, Laerum OD, Abyholm F. Altered polymorphonuclear neutrophilic granulocyte functions in patients with large burns. J Trauma. 1989;29:847-55.

48. Borregaard N. Neutrophils, from marrow to microbes. Immunity. 2010;33:657-70

49. Lacy P. Mechanisms of degranulation in neutrophils. Allergy Asthma Clin Immunol. 2006;2:98-108.

50. Weiss SJ. Tissue destruction by neutrophils. N Engl J Med. 1989;320:365-76.

51. Brinkmann V, Reichard U, Goosmann C, Fauler B, Uhlemann Y, Weiss DS, et al. Neutrophil extracellular traps kill bacteria. Science. 2004;303:1532-5.

52. Remijsen $\mathrm{Q}$, Vanden Berghe T, Wirawan E, Asselbergh B, Parthoens E, De Rycke $R$, et al. Neutrophil extracellular trap cell death requires both autophagy and superoxide generation. Cell Res. 2011;21:290-304.

53. Fuchs TA, Abed U, Goosmann C, Hurwitz R, Schulze I, Wahn V, et al. Novel cell death program leads to neutrophil extracellular traps. J Cell Biol. 2007;176:231-41.

54. Remijsen Q, Kuijpers TW, Wirawan E, Lippens S, Vandenabeele P, Vanden BT. Dying for a cause: NETosis, mechanisms behind an antimicrobial cell death modality. Cell Death Differ. 2011;18:581-8.

55. Yipp BG, Petri B, Salina D, Jenne CN, Scott BNV, Zbytnuik LD, et al. Infectioninduced NETosis is a dynamic process involving neutrophil multitasking in vivo. Nat Med. 2012;18:1386-93.

56. Menegazzi R, Decleva E, Dri P. Killing by neutrophil extracellular traps: fact or folklore? Blood. 2012;119:1214-6.

57. Liu F-C, Chuang Y-H, Tsai Y-F, Yu H-P. Role of neutrophil extracellular traps following injury. Shock. 2014;41:491-8.

58. Sayah DM, Mallavia B, Liu F, Ortiz-Muñoz G, Caudrillier A, Der Hovanessian A, et al. Neutrophil extracellular traps are pathogenic in primary graft dysfunction after lung transplantation. Am J Respir Crit Care Med. 2015;191:455-63.

59. Bosmann M, Ward PA. Protein-based therapies for acute lung injury: targeting neutrophil extracellular traps. Expert Opin Ther Targets. 2014;18:703-14.

60. Yipp BG, Kubes P. NETosis: how vital is it? Blood. 2013;122:2784-94.

61. Nauseef WM. Editorial: Nyet to NETs? A pause for healthy skepticism. J Leukoc Biol. 2012;91:353-5.
62. Adams MN, Ramachandran R, Yau MK, Suen JY, Fairlie DP, Hollenberg MD, et al. Structure, function and pathophysiology of protease activated receptors. Pharmacol Ther. 2011;130:248-82.

63. Steinhoff M, Buddenkotte J, Shpacovitch V, Rattenholl A, Moormann C, Vergnolle $\mathrm{N}$, et al. Proteinase-activated receptors: transducers of proteinasemediated signaling in inflammation and immune response. Endocr Rev. 2005;26:1-43.

64. Hartl D, Latzin P, Hordijk P, Marcos V, Rudolph C, Woischnik M, et al. Cleavage of CXCR1 on neutrophils disables bacterial killing in cystic fibrosis lung disease. Nat Med. 2007;13:1423-30.

65. Quaid G, Cave C, Robinson C, Williams MA, Solomkin J. Preferential loss of CXCR-2 receptor expression and function in patients who have undergone trauma. Arch Surg. 1999;134:1367-71. discussion 1371-2.

66. Cummings CJ, Martin TR, Frevert CW, Quan JM, Wong VA, Mongovin SM, et al. Expression and function of the chemokine receptors CXCR1 and CXCR2 in sepsis. J Immunol. 1999;162:2341-6.

67. Tarlowe MH, Duffy A, Kannan KB, Itagaki K, Lavery RF, Livingston DH, et al. Prospective study of neutrophil chemokine responses in trauma patients at risk for pneumonia. Am J Respir Crit Care Med. 2005;171:753-9.

68. Sadallah S, Hess C, Miot S, Spertini O, Lutz H, Schifferli JA. Elastase and metalloproteinase activities regulate soluble complement receptor 1 release. Eur J Immunol. 1999;29:3754-61.

69. van den Berg CW, Tambourgi DV, Clark HW, Hoong SJ, Spiller OB, McGreal EP. Mechanism of neutrophil dysfunction: neutrophil serine proteases cleave and inactivate the C5a receptor. J Immunol. 2014;192:1787-95.

70. van Kessel KPM, Bestebroer J, van Strijp JAG. Neutrophil-mediated phagocytosis of Staphylococcus aureus. Front Immunol. 2014;5:467.

71. Morris AC, Brittan M, Wilkinson TS, McAuley DF, Antonelli J, McCulloch C, et al. C5a-mediated neutrophil dysfunction is RhoA-dependent and predicts infection in critically ill patients. Blood. 2011;117:5178-88.

72. Le-Barillec K, Si-Tahar M, Balloy V, Chignard M. Proteolysis of monocyte CD14 by human leukocyte elastase inhibits lipopolysaccharide-mediated cell activation. J Clin Invest. 1999;103:1039-46.

73. Bank U, Reinhold D, Schneemilch C, Kunz D, Synowitz HJ, Ansorge S. Selective proteolytic cleavage of $\mathrm{IL}-2$ receptor and $\mathrm{IL}-6$ receptor ligand binding chains by neutrophil-derived serine proteases at foci of inflammation. J Interferon Cytokine Res. 1999;19:1277-87.

74. Matzinger P. An innate sense of danger. Semin Immunol. 1998;10:399-415

75. Scaffidi P, Misteli T, Bianchi ME. Release of chromatin protein HMGB1 by necrotic cells triggers inflammation. Nature. 2002;418:191-5.

76. Quintana FJ, Cohen IR. Heat shock proteins as endogenous adjuvants in sterile and septic inflammation. J Immunol. 2005;175:2777-82.

77. Bours MJL, Swennen ELR, Di Virgilio F, Cronstein BN, Dagnelie PC. Adenosine 5'-triphosphate and adenosine as endogenous signaling molecules in immunity and inflammation. Pharmacol Ther. 2006;112:358-404.

78. Kono $\mathrm{H}$, Chen CJ, Ontiveros F, Rock KL. Uric acid promotes an acute inflammatory response to sterile cell death in mice. J Clin Invest. 2010;120:1939-49.

79. Hazeldine J, Hampson P, Opoku FA, Foster M, Lord JM. N-formyl peptides drive mitochondrial damage associated molecular pattern induced neutrophil activation through ERK1/2 and P38 MAP Kinase signalling pathways. Injury. 2015;1-10.

80. Zhang Q, Raoof M, Chen Y, Sumi Y, Sursal T. Circulating mitochondrial DAMPs cause inflammatory responses to injury. Nature. 2010;464:104-7.

81. Kumar H, Kawai T, Akira S. Pathogen recognition by the innate immune system. Int Rev Immunol. 2011;30:16-34.

82. Forsman H, Önnheim K, Andréasson E, Christenson K, Karlsson A, Bylund J, et al. Reactivation of desensitized formyl peptide receptors by platelet activating factor: a novel receptor cross talk mechanism regulating neutrophil superoxide anion production. PLoS One. 2013;8:e60169.

83. Summers C, Rankin SM, Condliffe AM, Singh N, Peters M, Chilvers ER. Neutrophil kinetics in health and disease. Trends Immunol. 2010;31:318-24.

84. Pillay J, Ramakers BP, Kamp VM, Loi ALT, Lam SW, Hietbrink F, et al. Functional heterogeneity and differential priming of circulating neutrophils in human experimental endotoxemia. J Leukoc Biol. 2010;88:211-20.

85. Navarini AA, Lang KS, Verschoor A, Recher M, Zinkernagel AS, Nizet V, et al. Innate immune-induced depletion of bone marrow neutrophils aggravates systemic bacterial infections. Proc Natl Acad Sci U S A. 2009;106:7107-12 
86. Taneja R, Sharma AP, Hallett MB, Findlay GP, Morris MR. Immature circulating neutrophils in sepsis have impaired phagocytosis and calcium signaling. Shock. 2008;30:618-22.

87. Danikas DD, Karakantza M, Theodorou GL, Sakellaropoulos GC, Gogos CA. Prognostic value of phagocytic activity of neutrophils and monocytes in sepsis. Correlation to CD64 and CD14 antigen expression. Clin Exp Immunol. 2008;154:87-97.

88. Mare TA, Treacher DF, Shankar-Hari M, Beale R, Lewis SM, Chambers DJ, et al. The diagnostic and prognostic significance of monitoring blood levels of immature neutrophils in patients with systemic inflammation. Crit Care. 2015:19:1-11.

89. Cuenca AG, Delano MJ, Kelly-Scumpia KM, Moreno C, Scumpia PO, Laface DM, et al. A paradoxical role for myeloid-derived suppressor cells in sepsis and trauma. Mol Med. 2011;17:281-92.

90. Goh C, Narayanan S, Hahn YS. Myeloid-derived suppressor cells: The dark knight or the joker in viral infections? Immunol Rev. 2013;255:210-21.

91. Delano MJ, Scumpia PO, Weinstein JS, Coco D, Nagaraj S, Kelly-Scumpia KM, et al. MyD88-dependent expansion of an immature GR-1(+)CD11b(+) population induces T cell suppression and Th2 polarization in sepsis. J Exp Med. 2007;204:1463-74.

92. Pelletier M, Maggi L, Micheletti A, Lazzeri E, Tamassia N, Costantini C, et al. Evidence for a cross-talk between human neutrophils and Th17 cells. Blood. 2010;115:335-43.

93. Chertov O, Yang D, Howard OM, Oppenheim JJ. Leukocyte granule proteins mobilize innate host defenses and adaptive immune responses. Immunol Rev. 2000;177:68-78

94. Roghanian A, Drost EM, MacNee W, Howie SEM, Sallenave JM. Inflammatory lung secretions inhibit dendritic cell maturation and function via neutrophil elastase. Am J Respir Crit Care Med. 2006;174:1189-98.

95. Bank U, Ansorge S. More than destructive: neutrophil-derived serine proteases in cytokine bioactivity control. J Leukoc Biol. 2001;69:197-206.

96. Filardy AA, Pires DR, Nunes MP, Takiya CM, Freire-de-Lima CG, RibeiroGomes FL, et al. Proinflammatory clearance of apoptotic neutrophils induces an IL-12(low) IL-10(high) regulatory phenotype in macrophages. J Immunol. 2010;185:2044-50.

97. Langereis JD, Oudijk EJD, Schweizer RC, Lammers JWJ, Koenderman L, Ulfman LH. Steroids induce a disequilibrium of secreted interleukin-1 receptor antagonist and interleukin-1Beta synthesis by human neutrophils. Eur Respir J. 2011;37:406-15.

98. Noel G, Wang Q, Schwemberger S, Hanson C, Giacalone N, Haar L, et al. Neutrophils, not monocyte/macrophages, are the major splenic source of postburn IL-10. Shock. 2011;36:149-55.

99. Davey MS, Tamassia N, Rossato M, Bazzoni F, Calzetti F, Bruderek K, et al. Failure to detect production of IL-10 by activated human neutrophils. Nat Immunol. 2011;12:1017-8. author reply 1018-20.

100. Gabrilovich DI, Nagaraj S. Myeloid-derived suppressor cells as regulators of the immune system. Nat Rev Immunol. 2009:9:162-74.

101. Pillay J, Tak T, Kamp VM, Koenderman L. Immune suppression by neutrophils and granulocytic myeloid-derived suppressor cells: similarities and differences. Cell Mol Life Sci. 2013;70:3813-27.

102. Highfill SL, Rodriguez PC, Zhou Q, Goetz CA, Koehn BH, Veenstra R, et al. Bone marrow myeloid-derived suppressor cells (MDSC) inhibit graft-versushost (GVHD) disease via an arginase-1 dependent mechanism that is upregulated by IL-13. Blood. 2010;116:612-26.

103. Rodriguez PC, Quiceno DG, Ochoa AC. L-arginine availability regulates T-lymphocyte cell-cycle progression. Blood. 2007;109:1568-73.

104. Pillay J, Kamp VM, Van Hoffen E, Visser T, Tak T, Lammers J, et al. A subset of neutrophils in human systemic inflammation inhibits $T$ cell responses through Mac-1. J Clin Invest. 2012;122:327-36.

105. Darcy CJ, Minigo G, Piera KA, Davis JS, Mcneil YR, Chen Y, et al. Neutrophils with myeloid derived suppressor function deplete arginine and constrain $T$ cell function in septic shock patients. Crit Care. 2014;8(4):R163.

106. de Kleijn S, Langereis JD, Leentjens J, Kox M, Netea MG, Koenderman L, et al. IFN- $\gamma$-stimulated neutrophils suppress lymphocyte proliferation through expression of PD-L1. PLoS One. 2013;8:e72249.

107. Hotchkiss RS, Monneret G, Payen D. Sepsis-induced immunosuppression: from cellular dysfunctions to immunotherapy. Nat Rev Immunol. 2013;13:862-74

108. Brahmamdam P, Inoue S, Unsinger J, Chang KC, McDunn JE, Hotchkiss RS. Delayed administration of anti-PD-1 antibody reverses immune dysfunction and improves survival during sepsis. J Leukoc Biol. 2010;88:233-40.
109. Hampton HR, Bailey J, Tomura M, Brink R, Chtanova T. Microbe-dependent lymphatic migration of neutrophils modulates lymphocyte proliferation in lymph nodes. Nat Commun. 2015;6:7139.

110. Kamenyeva O, Boularan C, Kabat J, Cheung GYC, Cicala C, Yeh AJ, et al. Neutrophil recruitment to lymph nodes limits local humoral response to Staphylococcus aureus. PLoS Pathog. 2015;11, e1004827. 